\title{
Electric and Magnetic Signatures of Structural and Chemical Ordering of Heusler Alloy Films
}

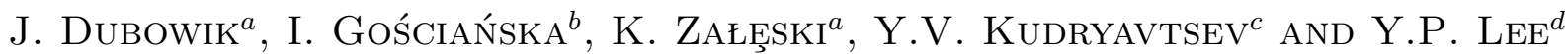 \\ ${ }^{a}$ Institute of Molecular Physics, Polish Academy of Sciences \\ M. Smoluchowskiego 17, 60-179 Poznań, Poland \\ ${ }^{b}$ Department of Physics, A. Mickiewicz University \\ Umultowska 85, 61-614 Poznań, Poland \\ ${ }^{c}$ Institute of Metal Physics, National Academy of Sciences of Ukraine \\ 252680, Kiev-142, Ukraine \\ ${ }^{d}$ q-psi and Department of Physics, Hanyang University, Seoul, 133-791 Korea
}

\begin{abstract}
We present results of in situ temperature measurements of resistivity for some amorphous or partially crystalline Heusler alloy films: $\mathrm{Co}_{2} \mathrm{CrAl}, \mathrm{Co}_{2} \mathrm{MnGa}$ and off-stoichiometric $\mathrm{Ni}_{2} \mathrm{Mn}_{1+x} \mathrm{Sn}_{x}, \mathrm{Ni}_{2} \mathrm{Mn}_{1-x} \mathrm{Ga}_{x}$ that are known to exhibit half-metallic properties and martensitic transformations, respectively. From $\rho$ vs. T characteristics we distinguish various stages of chemical and structural ordering in the films. They appear to be quite distinct in both systems investigated. The resistivity results are compared with magnetic characteristics for $\mathrm{Co}_{2} \mathrm{MnGa}$ with a high Curie temperature.
\end{abstract}

PACS numbers: 72.80.Ng, 73.61.-r, 75.70.-i, 76.50.+g

\section{Introduction}

Thin films of Heusler alloys (HA) are important for applications in spintronics or in devices based on shape memory effect (for review papers, see for example Refs. [1, 2]). Epitaxial HA films prepared by molecular-beam epitaxy have been shown to grow pseudomorphically on GaAs substrates with $L 2_{1}$ or $B 2$ structures [3]. Frequently, however, HA films have been deposited by sputtering $[4,5]$, laser ablation [6], or flash-evaporation [7] at room temperature (RT) with subsequent annealing. HA films deposited at RT or lower temperatures have, as a rule, highly disordered structure (amorphous or partially crystalline) [7] and chemical disorder significantly different from that of typical HA with $L 2_{1}$ or $B 2$ structure. In bulk HA ordering is typically achieved by annealing at temperatures as high as 1000-1300 K for many days, but in HA films such a procedure is obviously unacceptable. In this contribution we present the results of in situ resistivity measurements of several disordered HA films. We show how the ordering in HA films can be monitored with the resistivity measurements. Under proper annealing conditions, properties typical of bulk ordered HA counterparts can be almost fully restored. The results of resistivity measurements are compared with the magnetic characteristics of $\mathrm{Co}_{2} \mathrm{MnGa}$ films.

\section{Experimental and results}

Films of $\mathrm{Co}_{2} \mathrm{CrAl}, \mathrm{Co}_{2} \mathrm{MnGa}$ and off-stoichiometric $\mathrm{Ni}_{2} \mathrm{Mn}_{1+x} \mathrm{Sn}_{1-x}(x=0.4)$ were prepared by flash evap- oration [7] from HA powders of proper composition onto liquid nitrogen cooled glass substrates. The off-stoichiometric $\mathrm{Ni}_{2} \mathrm{Mn}_{1+x} \mathrm{Ga}_{1-x}(x=0.15,0.4)$ films were prepared by rf-sputtering at room temperature. The $\mathrm{Ni}-\mathrm{Mn}-\mathrm{Ga}$ and $\mathrm{Ni}-\mathrm{Mn}-\mathrm{Sn}$ films with off-stoichiometric composition were chosen since they reveal the martensitic transformation at higher temperatures than that of stoichiometric compounds [2]. Film thicknesses were between 100-200 nm except the sputtered $\mathrm{Ni}-\mathrm{Mn}-\mathrm{Ga}$ film with thickness of $2 \mu \mathrm{m}$ and were measured with Dectak profiler or by X-ray fluorescence (XRF). Film composition was determined with XRF. Structure of the films was determined with X-ray diffraction (XRD) using $\mathrm{Cu} K_{\alpha}$ or Co $K_{\alpha}$ radiation. The films were amorphous or partially crystalline except the $\mathrm{Ni}-$ Mn-Ga sputtered films in which XRD shows a single broad (220) peak typical of microcrystalline $A 2$ structure of fully disordered HA structure. In as-deposited state the films were nonmagnetic or very weakly magnetic $\left(\mathrm{Co}_{2} \mathrm{MnGa}\right)$ and after ordering they revealed crystalline $B 2$ or $L 2_{1}[7,8]$ or tetragonal [2] structure and show ferromagnetic ordering. The resistivity measurements were carried in situ in a high-vacuum chamber used for flash-evaporation at temperature varying from 300 to $800 \mathrm{~K}$ with a scan rate of $4 \mathrm{~K} / \mathrm{min}$. For Ni$\mathrm{Mn}-\mathrm{Ga}$ and $\mathrm{Ni}-\mathrm{Mn}-\mathrm{Sn}$ films with shape memory effect the resistivity measurements were also carried out from 200 to $400 \mathrm{~K}$ in a low-temperature setup. Magnetic measurements were performed using ferromagnetic resonance (FMR) spectrometer at $9.08 \mathrm{GHz}$ and vibrating sample 
magnetometer (VSM) at a temperature range from about $200 \mathrm{~K}$ up to $600 \mathrm{~K}$.

Figure 1 shows changes in the resistivity of $\mathrm{Ni}-\mathrm{Mn}-\mathrm{Ga}$, $\mathrm{Ni}-\mathrm{Mn}-\mathrm{Sn}, \mathrm{Co}_{2} \mathrm{CrAl}$ and $\mathrm{Co}_{2} \mathrm{MnGa}$ films during temperature cycling from 300 to $700-800 \mathrm{~K}$ and back to $300 \mathrm{~K}$. After high temperature cycling, we also performed additional $\rho(T)$ measurements in a temperature of 200 to $400 \mathrm{~K}$. Usually, upon crystallization of amorphous alloys, the resistivity decreases about twice [9] due to increase in structural and chemical ordering. In disordered $\mathrm{Ni}-\mathrm{Mn}-$ $\mathrm{Ga}(\mathrm{Sn})$ films, we observe a similar effect, however less noticeable: the resistivity decreases by $60-70 \%$. Comparing Fig. 1a with b, one can notice that disordered $\mathrm{Ni}_{-}^{-}$ $\mathrm{Mn}-\mathrm{Ga}$ films are more resistant to ordering than $\mathrm{Ni}-\mathrm{Mn}-$ Sn films, for which the resistivity decreases abruptly at about $520 \mathrm{~K}$ due to crystallization. This is in accordance with results of extended X-ray absorption fine structure (EXAFS) [10] measurements, which proved that the successive appearance of ferromagnetic and shape memory properties in annealed $\mathrm{Ni}-\mathrm{Mn}-\mathrm{Ga}$ films are related to the change in chemical ordering and then to an increase in crystalline grain structure, respectively. In the case of our $\mathrm{Ni}-\mathrm{Mn}-\mathrm{Ga}(\mathrm{Sn})$ films, the ferromagnetic ordering was achieved after full thermal cycle since in both films the characteristic "kinks" on $\rho(T)$ are clearly seen at the Curie temperature $T_{\mathrm{C}} \approx 380 \mathrm{~K}$ and $T_{\mathrm{C}} \approx 320 \mathrm{~K}$, respectively (see Fig. 1a and b). Inset in Fig. 1a shows $\rho(T)$ for a $\mathrm{Ni}_{1.92} \mathrm{Mn}_{1.48} \mathrm{Ga}_{0.6}$ film. The main features of $\rho(T)$ upon crystallization are similar to that of $\mathrm{Ni}_{1.94} \mathrm{Mn}_{1.21} \mathrm{Ga}_{0.85}$ film but after ordering at $\approx 800 \mathrm{~K}$ a hysteretic anomalous jump in $\rho$ is seen at temperature range of 300-400 K. This is typical of martensitic transformation in $\mathrm{Ni}-\mathrm{Mn}-$ Ga films with shape memory effect [11].

In Figs. 1c and d it is seen that for $\mathrm{Co}_{2} \mathrm{CrAl}$ and $\mathrm{Co}_{2} \mathrm{MnGa}$ films $\rho(T)$ characteristics are significantly different from that of $\mathrm{Ni}-\mathrm{Mn}-\mathrm{Ga}(\mathrm{Sn})$ films. The resistivity of amorphous $\mathrm{Co}_{2} \mathrm{CrAl}$ film abruptly increases at $T \approx 500 \mathrm{~K}$ and after ordering it attains higher values. Moreover, after ordering at $600-700 \mathrm{~K}$ the temperature coefficient of resistivity TCR $>0$ in accordance with earlier observations [12] for $L 2_{1}$ ordered bulk $\mathrm{Co}_{2} \mathrm{CrAl}$. On crystallization and ordering of the amorphous $\mathrm{Co}_{2} \mathrm{MnGa}$ film the resistivity also increases, however in a different way. Figure $1 \mathrm{~d}$ shows clearly that at $\approx 430 \mathrm{~K}$, the electrical resistivity experiences a substantial jump-like increase and then at $\approx 500 \mathrm{~K}$, it decreases in a similar way but attains values by about $30 \%$ higher than those in the amorphous state. With independent XRD and transmission electron microscopy (TEM) measurements [8] we checked that low-temperature annealing at $\approx 500 \mathrm{~K}$ leads to a very inhomogeneous mixed phase consisting of $\mathrm{Co}_{2} \mathrm{MnGa}$ and $\epsilon-\mathrm{Mn}_{3} \mathrm{Ga}$ (and/or $\mathrm{Mn}_{3} \mathrm{Co}_{7}$ ) phases.

Annealing of our HA films can restore single phase ordered HA structures, which are ferromagnets with the Curie temperatures typical of bulk alloys. Due to limited space, we would like to discuss more thoroughly characteristic changes in magnetic properties during the crystallization process of the amorphous $\mathrm{Co}_{2} \mathrm{MnGa}$ films and to

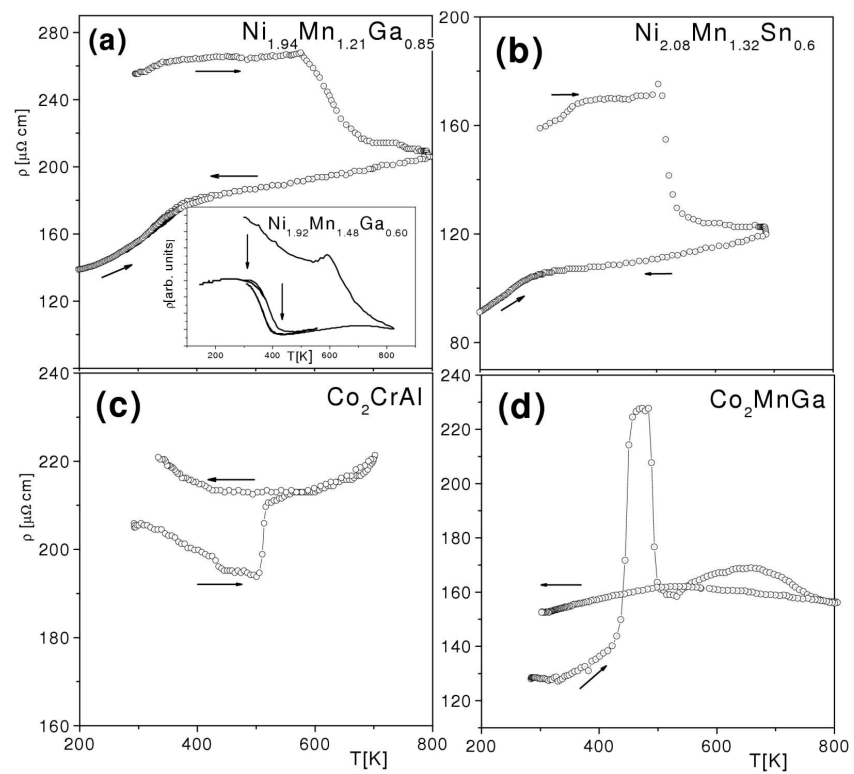

Fig. 1. Exemplary temperature changes in resistivity $\rho$ for the disordered $\mathrm{Ni}-\mathrm{Mn}-\mathrm{Ga}$ (a), Ni-Mn-Sn (b), $\mathrm{Co}_{2} \mathrm{CrAl}$ (c), $\mathrm{Co}_{2} \mathrm{MnGa}$ (d) on high temperature cycling. Inset in (a) shows $\rho(T)$ characteristic with a hysteretic behavior between 300 and $420 \mathrm{~K}$ typical of ordered off-stoichiometric $\mathrm{Ni}-\mathrm{Mn}-\mathrm{Ga}$ alloys.

compare them with the resistivity data shown in Fig. 1d. Since the Curie temperature of the ordered $\mathrm{Co}_{2} \mathrm{MnGa}$ is of $690 \mathrm{~K}$, it is possible to monitor in situ the changes in the magnetic characteristics of the disordered film in the course of heating and cooling back to RT. Figures 2a and $b$ show the temperature dependence of the effective magnetization $4 \pi M_{\text {eff }}$ and saturation magnetization $M_{\mathrm{S}}$, respectively. $4 \pi M_{\text {eff }}$ and $M_{\mathrm{S}}$ were derived from FMR and VSM measurements, respectively. The amorphous $\mathrm{Co}_{2} \mathrm{MnGa}$ is already very weakly magnetic: there is seen a weak FMR signal though it has practically no magnetic moment measured with VSM. It is seen that $4 \pi M_{\text {eff }}$ also experiences substantial changes in the same temperature range as the resistivity (Fig. 1d). As shown in Fig. 2b, the saturation magnetization $M_{\mathrm{S}}$ does not change until about $500 \mathrm{~K}$ and then begins to increase to a value of $250 \mathrm{G}$ in a range of $500-600 \mathrm{~K}$. It is reasonable to conclude that crystallization of the amorphous $\mathrm{Co}_{2} \mathrm{MnGa}$ films, occurring below $\approx 520 \mathrm{~K}$, leads to a strongly inhomogeneous polycrystalline structure in accordance with the resistivity measurements. Further ordering leads to an enhancement of the magnetic characteristics of the $\mathrm{Co}_{2} \mathrm{MnGa}$ films: the RT values of $4 \pi M_{\text {eff }}$ increase up to $6000 \mathrm{G}$ and $M_{\mathrm{S}}$ to $\approx 500 \mathrm{G}$. To conclude, our resistivity and magnetic measurements of the amorphous $\mathrm{Co}_{2} \mathrm{MnGa}$ films at elevated temperatures show clearly nonmonotonic changes resulting from appearance of mixed phases at $520 \mathrm{~K}$ followed by further homogenization and ordering at $T \approx 600 \mathrm{~K}$. 


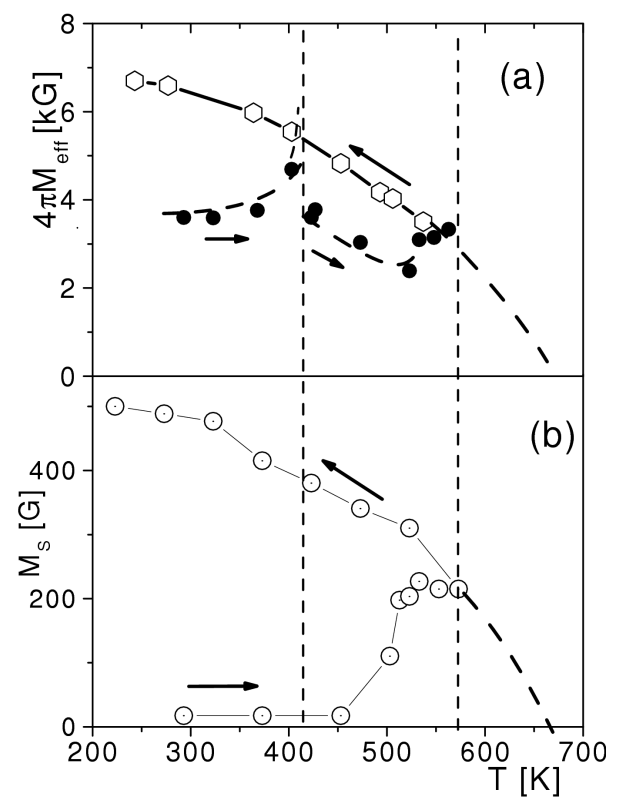

Fig. 2. (a) Changes of the effective magnetization $4 \pi M_{\text {eff }}$ and (b) in the saturation magnetization $M_{\mathrm{S}}$ of an amorphous $\mathrm{Co}_{2} \mathrm{MnGa}$ film in the course of heating and cooling back to RT.

\section{Conclusions}

We investigated high temperature resistivity in amorphous $\mathrm{Co}_{2} \mathrm{MnGa}, \mathrm{Co}_{2} \mathrm{CrAl}$ and partially crystalline off-stoichiometric Ni-Mn-Ga, Ni-Mn-Sn films. Structural disorder severely affects the conduction electron mean free path as well as the exchange interactions resulting in the high resistivity and the lack of ferromagnetic ordering. Generally, at temperatures of $\approx 500 \mathrm{~K}\left(\mathrm{Co}_{2} \mathrm{MnGa}\right.$, $\left.\mathrm{Co}_{2} \mathrm{CrAl}\right)$ or $\approx 600 \mathrm{~K}(\mathrm{Ni}-\mathrm{Mn}-\mathrm{Ga}, \mathrm{Ni}-\mathrm{Mn}-\mathrm{Sn})$ the films crystallize. However, our results show that chemical and structural ordering may have diverse effect on high temperature characteristics of HA films. Resistivity may decrease almost monotonically over a wide temperature range from 600 to $700 \mathrm{~K}(\mathrm{Ni}-\mathrm{Mn}-\mathrm{Ga})$. It may drop $(\mathrm{Ni}-\mathrm{Mn}-\mathrm{Sn})$ or rise $\left(\mathrm{Co}_{2} \mathrm{CrAl}\right)$ in a narrow temperature range or it may show a characteristic maximum $\left(\mathrm{Co}_{2} \mathrm{MnGa}\right)$ due to appearance of mixed phases, which were confirmed with the magnetic measurements. In conclusion, high temperature resistivity measurement is a sensitive tool for tracing the chemical and structural ordering in HA films.

\section{References}

[1] C. Felser, G.H. Fecher, B. Balke, Angew. Chem. Int. Ed. 46, 668 (2007).

[2] J. Dubowik, I. Gościańska, A. Szlaferek, Y.V. Kudryavtsev, Mater. Sci. Poland 25, 583 (2007).

[3] C. Palmstrom, MRS Bulletin, October 2003, p. 725.

[4] I. Takeuchi, O.O. Famadu, J.C. Read, M.A. Aronova, K.-S. Chang, C. Craciunescu, S.E. Lofland, M. Wuttig, F.C. Wellstood, L. Knauss, A. Orozco, Nature Mater. 2, 180 (2003).

[5] J. Schmalhorst, S. Kämmerer, M. Sacher, G. Reiss, A. Hütten, A. Scholl, Phys. Rev. B 70, 024426 (2004).

[6] E. Valerio, C. Grigorescu, S.A. Manea, F. Guinnetou, W.R. Bradford, M. Autric, Appl. Surf. Sci. 247, 151 (2005).

[7] Y.V. Kudryavtsev, V.N. Uvarov, V.A. Oksenenko, Y.P. Lee, J.B. Kim, Y.H. Hyun, K.W. Kim, J.Y. Rhee, J. Dubowik, Phys. Rev. B 77, 195104 (2008).

[8] Y.V. Kudryavtsev, V.A. Oksenenko, Y.P. Lee, Y.H. Hyun, J.B. Kim, J.S. Park, S.Y. Park, J. Dubowik, Phys. Rev. B 76, 024430 (2007).

[9] K.V. Rao, in: Amorphous Metallic Alloys, Ed. F.E. Luborsky, Butterworths, London 1983, p. 398.

[10] H. Rumpf, C.M. Craciunescu, H. Modrow, Kh. Olimov, E. Quandt, M. Wuttig, J. Magn. Magn. Mater. 302, 421 (2006).

[11] M. Kohl, D. Brugger, M. Ohtsuka, T. Takagi, Sens. Actuators A 114, 445 (2004).

[12] A. Husmann, L.J. Singh, Phys. Rev. B 73, 172417 (2006). 